\title{
Experimental analysis in frequency domain of the accelerations induced by different vehicles in high speed railway tracks
}

\author{
José Conrado Martínez-Acevedo ${ }^{1}$, Miguel Rodríguez-Plaza ${ }^{1}$, Clara zamorano ${ }^{2}$, \\ Fran Ribes-Llario ${ }^{3}$, Julia Irene real ${ }^{3}$ \\ ${ }^{I}$ Innovation and Technology Direction. Administrator of Railway Infrastructures ADIF. 28045, Madrid, Spain \\ ${ }^{2}$ Foundation for the Research and Engineering in Railways, 28002 Madrid, Spain \\ ${ }^{3}$ University Institute for Multidisciplinary Mathematics, Polytechnic University of Valencia, 46022, Valencia, \\ Spain
}

\begin{abstract}
The accelerations induced by different vehicles in the track are studied in the frequency domain from data collected in an extensive measurement campaign in the high speed line Madrid-Barcelona-French Border. In the first section, it will be determined which vehicle induces higher accelerations in the infrastructure taking into account the train model, speed and vehicle configuration (simple or double). Then, the vibration response will be described for the different vehicles running on the track, identifying the contribution of the quasi-static load as well as different dynamic effects typical from ballasted high speed railway tracks. Therefore, the frequency bands in which the different dynamic excitation may appear are calculated, collating the results with the measured accelerations and establishing a cause-effect relationship in the different acceleration spectra.
\end{abstract}

Keywords: Ballasted Track, High-speed train, Railway, vibrations

\section{Introduction}

High speed railways have experienced an important growth in many developed countries in recent years. The need of improving the safety and the comfort, expanding the life span and increasing the capacity has motivated the huge investment of resources in order to achieve a better understanding of the dynamic behavior of this type of infrastructures.

The first exhaustive experimental research on vibrations in high speed railways was conducted by Degrande and Schillemans (2001). They measured vibrations in the track and in the surrounding ground during nine different vehicle passages in the high speed line Paris-Brussels. In the same line, Xia et al. (2003) studied the dynamic behavior of a railway bridge; strains and accelerations were measured in the infrastructure during the passage of the vehicles. In Germany, Auersch $(2005,2006)$ directed experimental campaigns to record ground accelerations induced by the passage of different vehicles in the high speed line Berlin-Hannover. Moreover, these data have been used to develop vehicle-track-soil interaction models in addition to other wave propagation models.

Experimental acceleration data have also been used to develop dynamic models to predict vibrations by Galvín and Domínguez $(2007,2009)$. In these cases, numerical models based on the Finite Elements Method and the Boundary Elements Method, were validated with real measurements to predict vibrations in the ground and study the interaction with structures. Other predictive models validated from experimental records from high speed lines can be found in Lombaert et al. (2006) and Conolly et al. (2014). In these cases, the models are used to calculate the soil response during the train passage and the indoor noise in nearby buildings respectively.

From the previous literature review, it is deduced that real registers are essential for the development of acceleration prediction models in railways. On the other hand, most of the existing work is focused on the study of train induced vibrations in the nearby soil, while vibration in the track elements (i.e. rail, sleepers and ballast) may compromise the durability of the infrastructure. Consequently, the vibration of the track infrastructure elements requires special attention. Among the authors who establish a correspondence between track vibrations and durability, López Pita et al. (2004) and Kaewunruen and Remennikov (2008) should be mentioned. The first work points the ballast layer vibration as one of the fundamental causes of the degradation of the track and the loss of vertical stiffness while the second study mentions the importance of the sleeper vibration as an indicator of the real condition of the whole track.

In this paper, the experimental results of an acceleration measurement campaign in a high speed track are presented. The dynamic effects of the passages of 36 trains of different types operating at different speeds were recorded. From the processed results, it is assessed the influence of the vehicle type and the speed on the accelerations induced in several points of the track: rail, sleepers and sub-ballast. Secondly, the acceleration results obtained in the different cases are related to the excitation mechanisms that produces them. To achieve this goal, an exhaustive analysis is performed in the frequency domain. 


\section{Data acquisition campaign}

The acceleration measurement campaign took place during three consecutive days in July, 2014 in the Research and Development Laboratory owned by ADIF near Guadalajara in the high speed line MadridBarcelona-French Border. The lab is located in the sub-line Madrid-Zaragoza, which was opened to transit in October, 2003. Fig. 1 shows a picture of the measured track section which is located just in front of the lab.

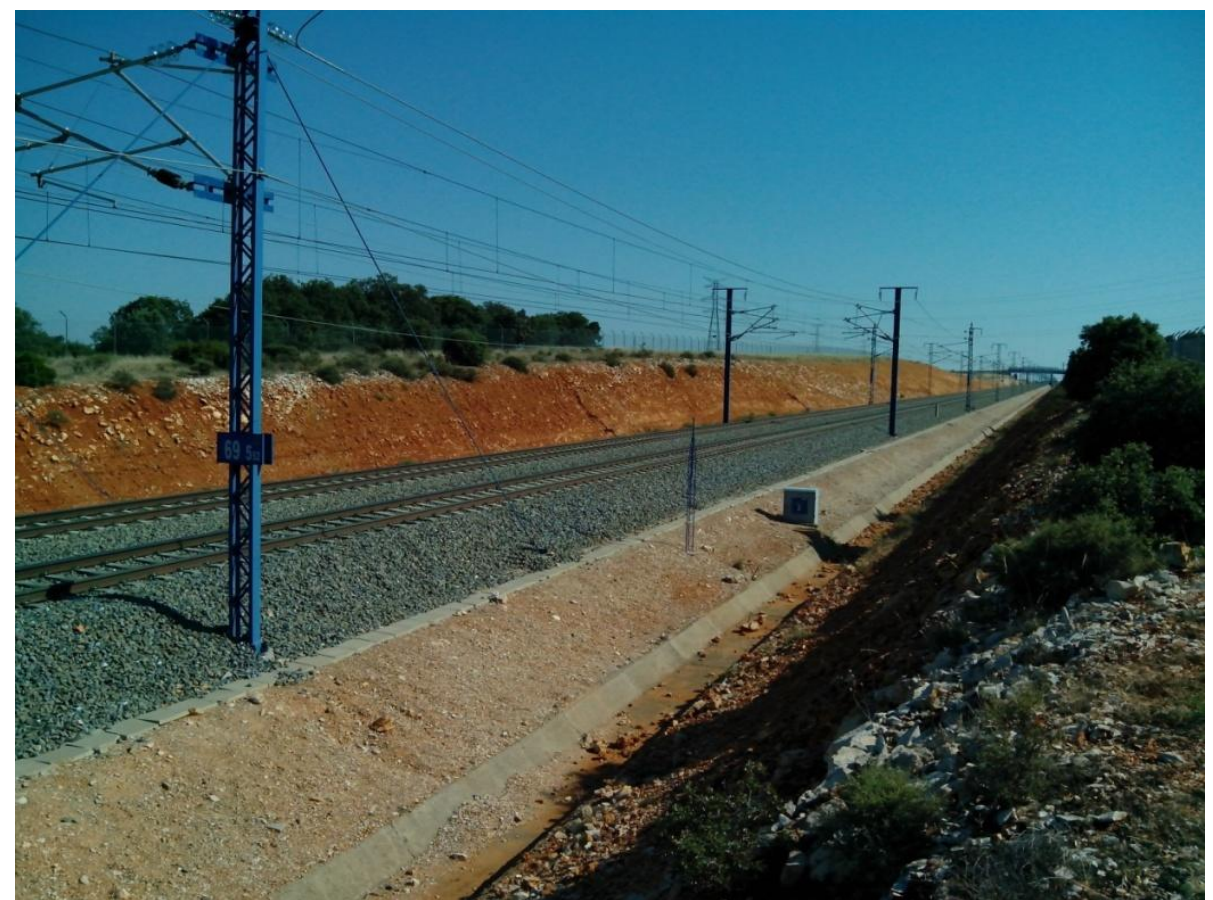

Fig.1.Monitored track section in the high speed line Madrid-Barcelona-French Border

\subsection{Track properties}

This high speed line is a double ballasted track with international gauge. The rail is UIC-60, supported by a railpad of $100 \mathrm{kN} / \mathrm{mm}$. The sleepers are made of prestressed concrete, the gap between two consecutive sleepers is $0.6 \mathrm{~m}$ and they lie on a $0.75 \mathrm{~m}$ thick ballast layer. Under the ballast layer, there is a $0.3 \mathrm{~m}$ thick granular layer (sub-ballast) in which the ducts are embedded. The whole track superstructure lies on the natural ground which is composed mainly by limestone. The track section is schematically depicted in Fig. 2.

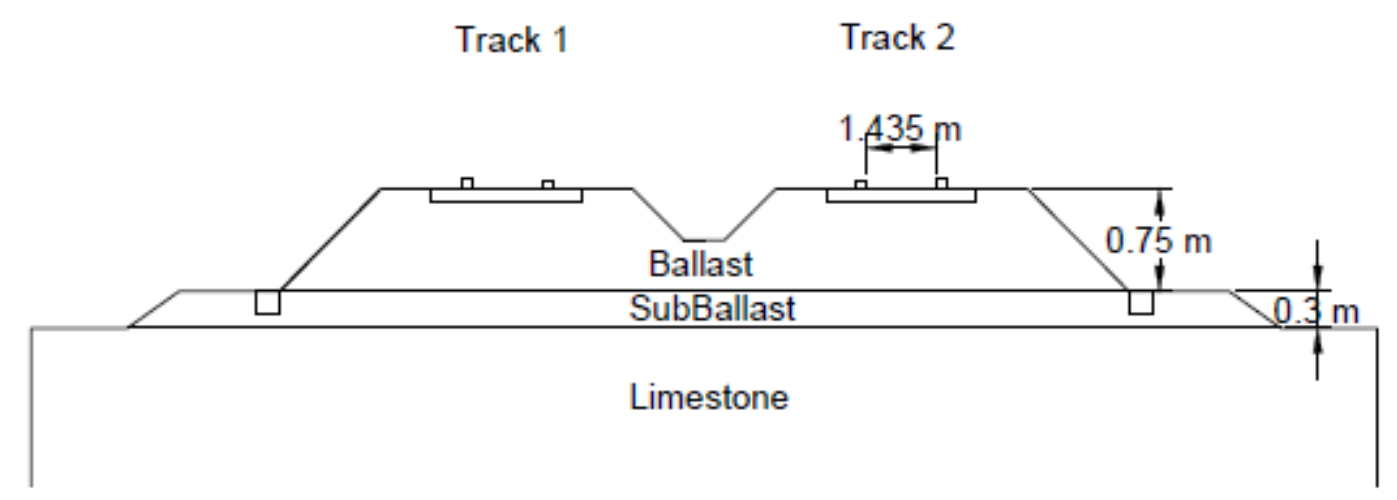

\subsection{Track monitoring}

Fig.2. Cross section of the monitored track

In the same cross-section of track 2, four different points were monitored: the rail web, the center of the sleeper, the top of the sleeper and the sub-ballast. The devices used in each of the four points were piezoelectric accelerometers PCB 354C02 with a sampling frequency of $10000 \mathrm{~Hz}$ and a maximum peak range of $\pm 500 \mathrm{~g}$. The accelerometers were attached to the track elements using a magnetic base of neodymium. For this reason, was also necessary to fix metal plates to the concrete sleeper using epoxy adhesive and to drive a $0.3 \mathrm{~m}$ steel pike in the sub-ballast. The resulting disposition of the accelerometers is shown in fig. 3 . 

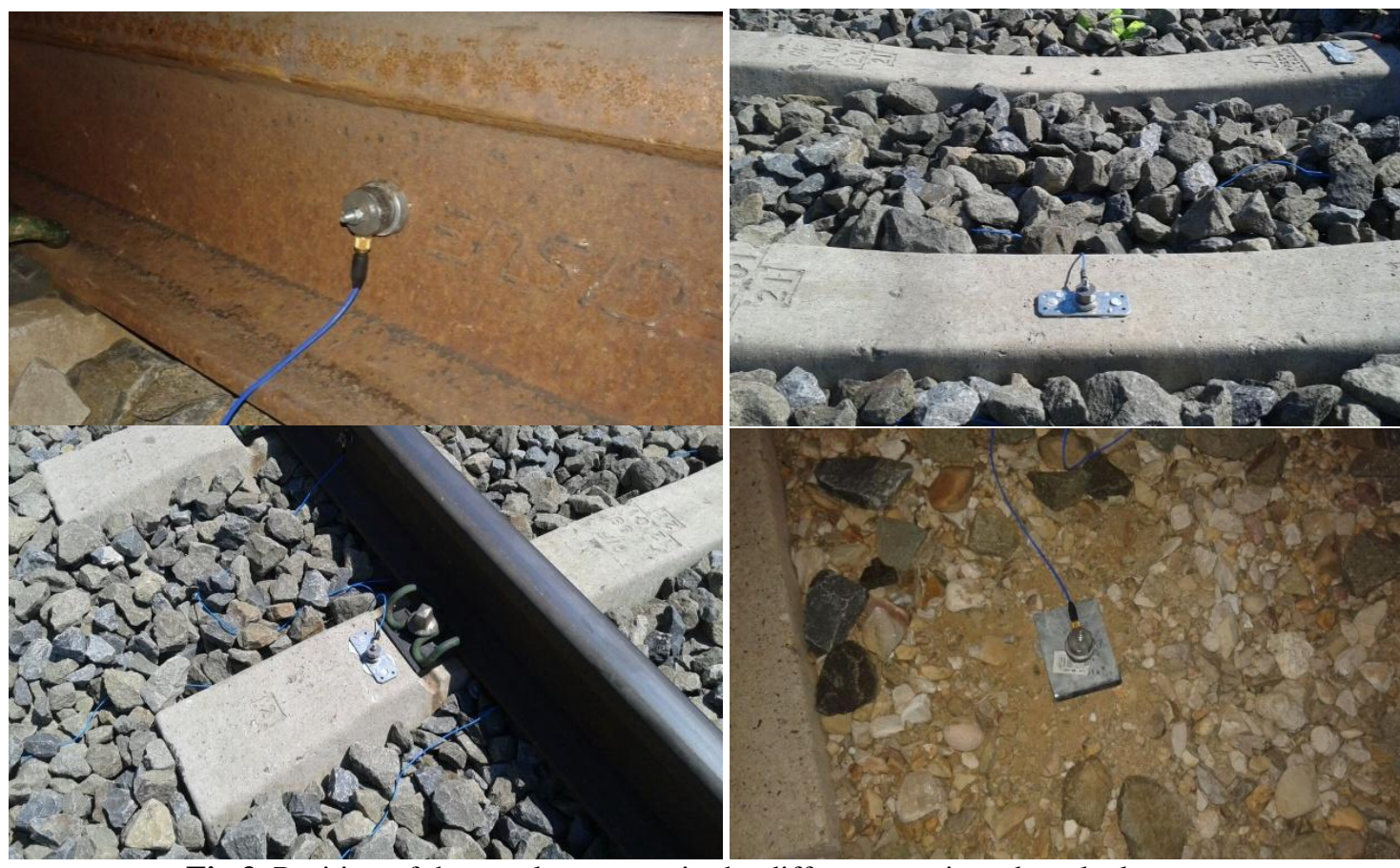

Fig.3. Position of the accelerometers in the different monitored track elements

During the campaign, 36 different passages were measured. These passages correspond to trains of different types rolling at different speeds towards Madrid. A summary of the registered trains is available in table 1.

\begin{tabular}{|c|c|c|c|}
\hline Official Name & Vehicle & Configuraton & TOTAL \\
\hline S-102/S-112 & Talgo T-350 & SIMPLE & 7 \\
\cline { 3 - 4 } & & DOUBLE & 3 \\
\hline S-103 & Siemens Velaro E & SIMPLE & 17 \\
\cline { 3 - 4 } & & DOUBLE & 3 \\
\hline S-120 & CAF 120 & SIMPLE & 6 \\
\hline
\end{tabular}

Tabla 1. Summary of the trains recorded during the data acquisition campaign

\subsection{Characteristics of the studied vehicles}

The axle distribution of the different vehicles studied is represented in fig. 4.
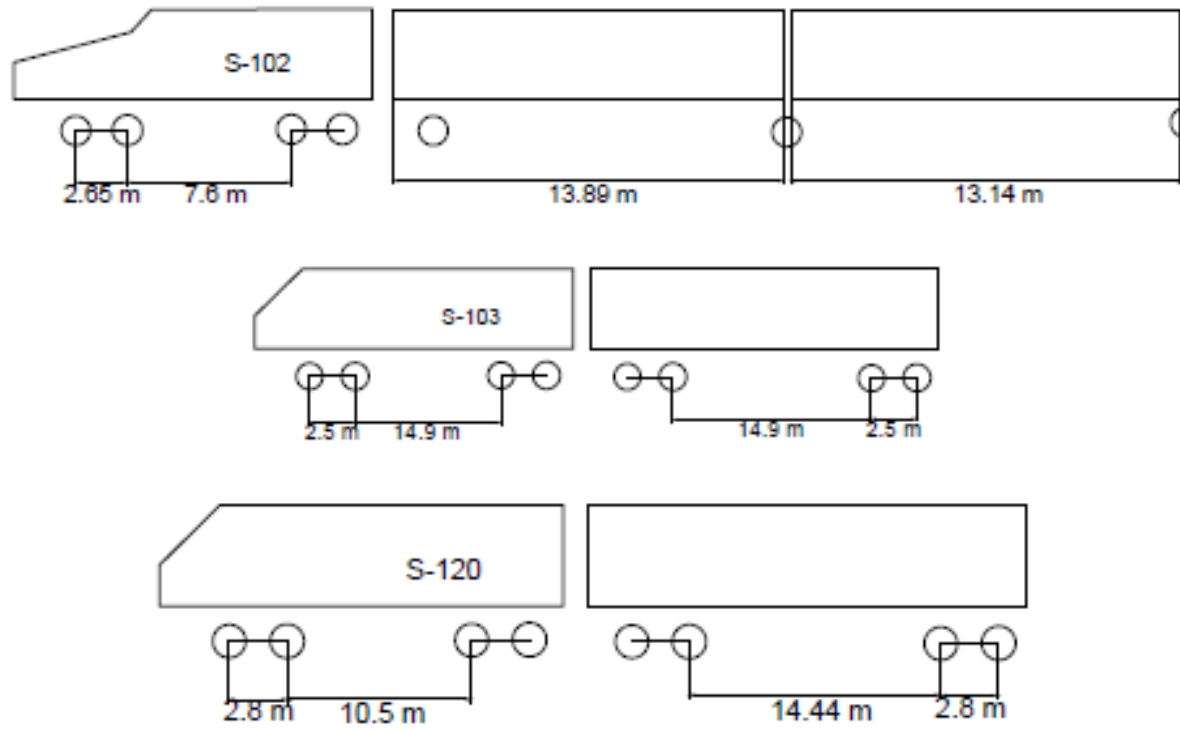

Fig.4. Sketch of the locomotives and carriages of the different high speed trains 
The vehicle S-102 consists of two locomotives at the ends of the train and 12 passenger carriages placed in between. There are two types of passenger carriages: extreme and central. In a complete train, there are two extreme carriages linked to the locomotives and the 10 central passenger cars are located in the center of the train. It must be mentioned that the axles are mounted in bogies only in the locomotive while in the central carriages there are individual axles between the passenger carriages.

The vehicle S-103 has two locomotives at the ends and six central carriages. In both cases, the axles are mounted in bogies as shown in fig. 4. As in the S-102, the double configuration is obtained coupling directly two locomotives.

Finally, the vehicle S-120 has two head carriages and two central carriages. All the bogies in this vehicle are motor bogies.

\section{Influence of the vehicle type and the speed}

In order to study the influence of the vehicle type and the speed on the accelerations induced on the infrastructure, each of the vehicles presented in section 2.3 was divided into three groups: simple-fast, simpleslow and double fast. Fast trains pass at a speed between 260 and $305 \mathrm{~km} / \mathrm{h}$ while the slow trains do it in the range $215-260 \mathrm{~km} / \mathrm{h}$.

The power spectral density (PSD) has been calculated for each acceleration register. To do so, the recorded signal is transformed to the frequency domain by means of the Discrete Fourier Transform. In this manner, 36 different spectra are obtained and its mean average PSD is calculated according to Eq. (1):

$$
\overline{P S D}_{A}=\sum_{k=1}^{M} \sum_{i=1}^{N} \frac{\left|X_{i}^{k}\right|}{N * M}
$$

Where Xik is the PSD of the k-th train en la i-th frequency. In this manner, $\mathrm{k}$ will be determined by the number of trains of each type (see table 1) and the index i varies in the range 1-5000 Hz (Nyquist frequency) since the sampling frequency was $10000 \mathrm{~Hz}$.

This formula is based on the one defined by Xianzhang et al. (2009) but re-defined in frequency domain to obtain homogeneous values. In this manner, the trains with the lowest number of records different from zero are not underestimated (i.e. fast trains and simple trains whose accelerograms have less values different from zero than those produced by slow and simple trains respectively). The final results are shown in fig. 5 .

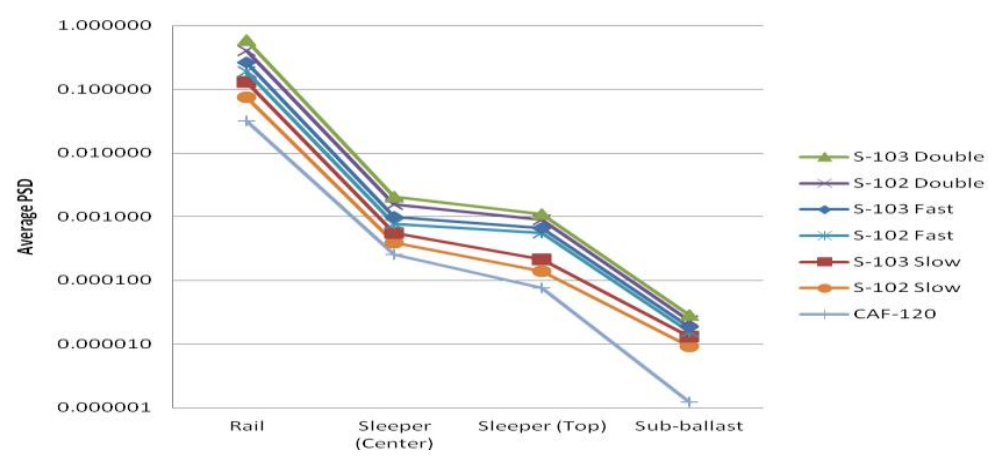

Fig.5. Mean average PSD for the different type of vehicles and speeds

As a first conclusion, it can be asserted that the high speed vehicles transmit more energy to the track than the vehicle S-120. Moreover, the double composition trains have higher mean average PSD than the simple trains; among the simples, the fast trains are always above the slow trains in fig. 5. Finally, it should be mentioned that S-103 trains present a slightly higher mean average PSD than the S-102 trains regardless of the three studied types.

A possible explanation to the fact that S-103 trains have higher mean average PSD than the S-102 trains can be found in the differences in net weight: the mass of the empty S-102 train is $322 \mathrm{t}$ while for the S103 train is 425 t. For this reason, assuming a mass of the unsprung masses proportional to the total mass, the accelerations induced by the second will be higher as deduced from fig. 5 .

Fig. 5 also reflects how the vibration energy vanishes as the wave passes from one track element to another. The sleeper is constrained between the railpad and the ballast layer, and these elements have a great vibration mitigation power; for this reason the mean average PSD in the sleeper is two orders of magnitude lower than in the case of the rail. Analogously, as a consequence of the damping of the granular material in the ballast and sub-ballast layers, the mean average PSD of the vertical accelerations in the sub-ballast drop up to four orders of magnitude with regard to the rail. 


\section{Detailed study of the vibrations}

Once the different passages have been classified according to the PSD of the accelerations induced on the track, the frequency content of the registers associated to each type of train is studied. To do so, a representative acceleration register is chosen for each of the train types presented in table 1 .

As the mean average PSD has already been calculated in the previous section, the representative acceleration register of each group will be chosen as the one with the mean average PSD closer to the mean average PSD of the group. Moreover, the coefficient of variation of the mean average PSD for all the registers is below 1, what ensures that the mean average PSD is a representative statistic of the sample. In table 2, the representative passages for each group are identified with the day and the hour when the accelerations were registered.

\begin{tabular}{|c|c|c|c|}
\hline Official Name & Train type & Passage & Speed (km/h) \\
\hline \multirow{3}{*}{ S-102/S-112 } & SIMPLE (Fast) & Day $15^{\text {th }}-17: 31 \mathrm{~h}$ & 298 \\
\cline { 2 - 4 } & SIMPLE (Slow) & Day $16^{\text {th }}-10: 07 \mathrm{~h}$ & 227 \\
\cline { 2 - 4 } & DOUBLE & Day $16^{\text {th }}-11: 18 \mathrm{~h}$ & 289 \\
\hline \multirow{2}{*}{ S-103 } & SIMPLE (Fast) & Day $16^{\text {th }}-09: 57 \mathrm{~h}$ & 300 \\
\cline { 2 - 4 } & SIMPLE (Slow) & Day $15^{\text {th }}-12: 40 \mathrm{~h}$ & 215 \\
\cline { 2 - 4 } & DOUBLE & Day $15^{\text {th }}-13: 19 \mathrm{~h}$ & 290 \\
\hline S-120 & SIMPLE & Day $15^{\text {th }}-14: 03 \mathrm{~h}$ & 168 \\
\hline
\end{tabular}

Table 2. Representative passages for each train type group

Degrande and Schillemans (2001) stated that the accelerations in the rail have too wide frequency spectrum and that the effect of the quasi-static load (axles and bogies) disappears in the ground registers. For these reasons, the acceleration registers in the center of the sleepers have been chosen to study the effect of the passage of axles and bogies as well as dynamic phenomena. In addition, De Man (2002) set in $1500 \mathrm{~Hz}$ the threshold below which all the resonant events occur in a ballasted track. Consequently, the upper limit of the dynamic effects is $1500 \mathrm{~Hz}$ in this analysis.

\subsection{Analysis of the quasi-static load}

The acceleration registers in the frequency domain for the different train types presented in table 2 are depicted in fig.6.

a)

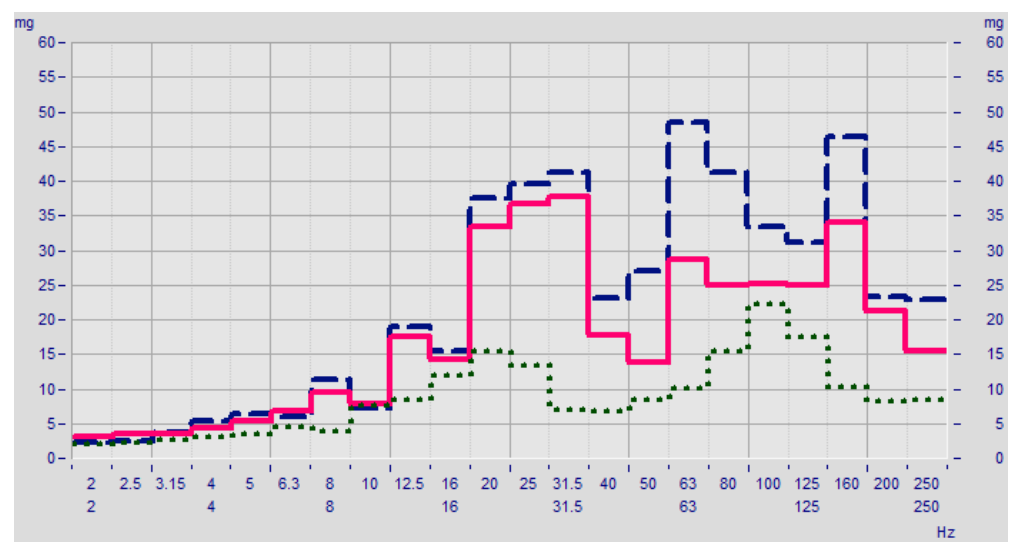

b)

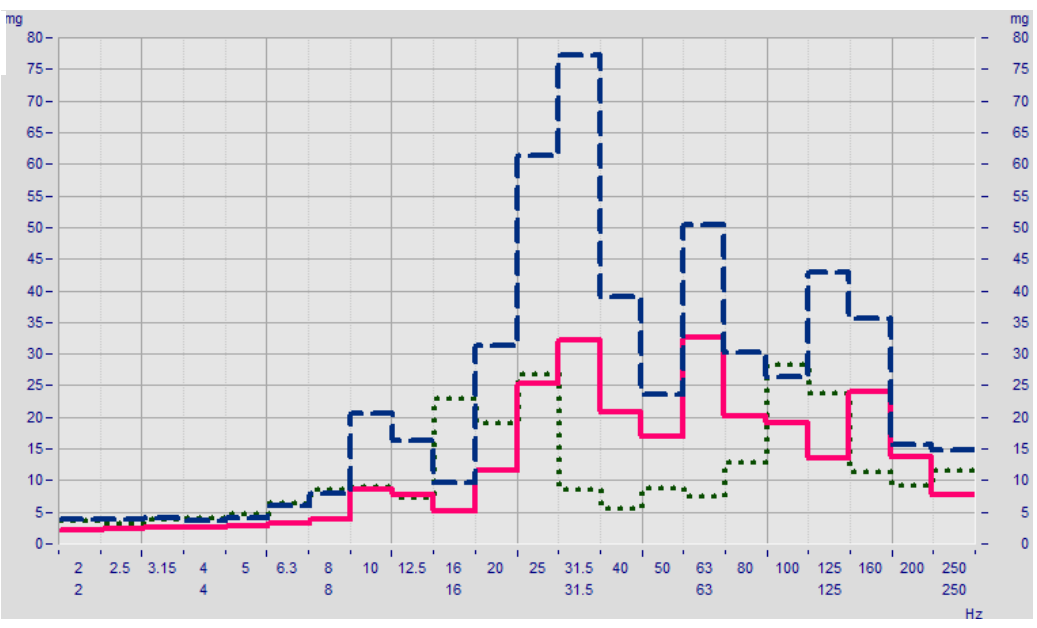


c)

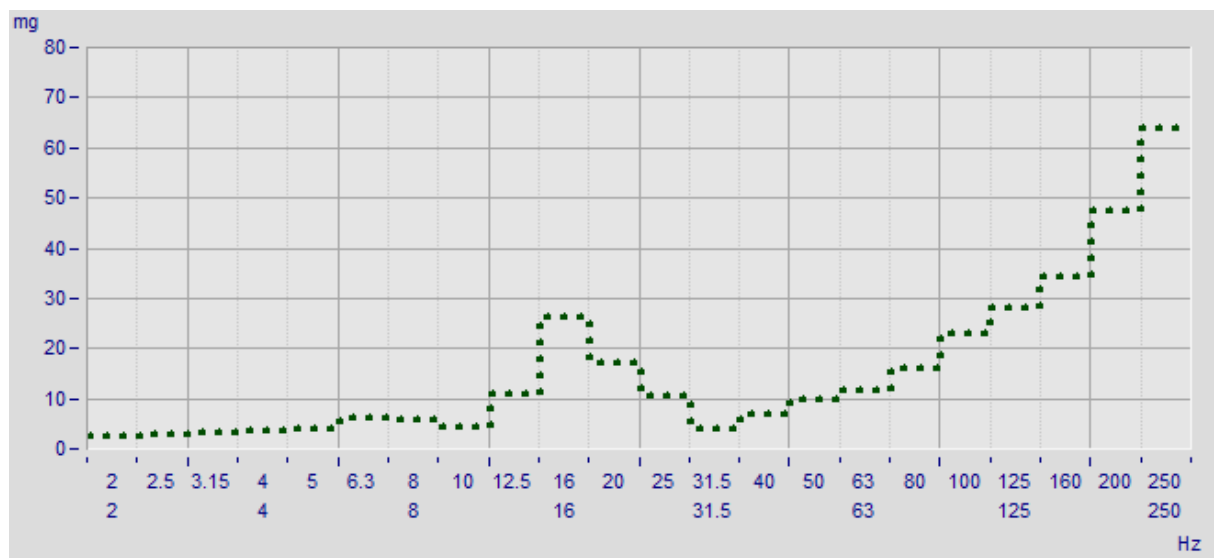

Fig.6. Accelerations on the sleeper center represented in third-octave bands for the Vehicle S-102 (a); S-103 (b); S-120 (c). Fast train( $\square)$, Slow train $(\cdots)$, Double Train (---).

The frequencies associated to the passage of the axles and the bogies for each type of vehicle can be calculated according to Eq. 2:

$$
f=\frac{v}{l}
$$

Where $\mathrm{v}$ is the train speed in from table 2 and 1 the separation between axles and bogies represented in fig. 4. All the results calculated with Eq.2 are grouped in table 3. It must be mentioned that the vehicle S-102 only has bogies in the locomotives; therefore, the passing frequency related to the bogie passage has been calculated attending to the distance between the axles located in the central carriages.

\begin{tabular}{|c|c|c|c|}
\hline & & Axle Passage & Bogie Passage \\
\hline \multirow{3}{*}{ S-102 } & Fast & 31,2 & 6,3 \\
\cline { 2 - 4 } & Slow & 23,8 & 4,8 \\
\cline { 2 - 4 } & Double & 30,3 & 6,1 \\
\hline \multirow{3}{*}{ S-103 } & Fast & 33,3 & 4,8 \\
\cline { 2 - 4 } & Slow & 23,9 & 3,4 \\
\cline { 2 - 4 } & Double & 32,2 & 4,6 \\
\hline S-120 & Unique & 16,7 & 2.7 \\
\hline
\end{tabular}

Table 3. Frequencies related to the passage of the quasi-static load $(\mathrm{Hz})$

The frequencies corresponding to the axle passage can be easily identified in the plots in fig.6. Regardless of the vehicle type, the frequency bands corresponding to these frequencies have higher values than their adjacent. Additionally, the excitation associated to the bogie passage does not result as evident in the case of the fast and double trains; in this case, it appears displaced to adjacent bands as a possible consequence of the Doppler Effect (Ditzel et al. 2001). Since the frequencies increase with the train speed and the lower frequency bands are very narrow, this is a suitable explanation for the differences existing between the calculated and registered values.

According to Auersch (2005), the frequency representation of the excitation produced by a train passage changes as the number of axles increases, producing relative maximums at frequencies which are natural multiples of the frequency associated to the passage of an axle. This phenomenon is evidenced in fig. 6 a) and b), where there are relative maximums in the frequency bands which are multiple of those containing the frequencies related to the axle passage. For instance, in the case of the vehicle S-103 double, it can be seen a maximum in the $31.5 \mathrm{~Hz}$ band and relative maximums in the 63 and $125 \mathrm{~Hz}$ bands. As deduced from Auersch (2010), the greater homogeneity in the axle and bogie distribution of the train S-103 causes that the results obtained in the frequency domain are easier to interpret than in those for the vehicle S-102.

Based on figs.6 a) and b), it can be inferred that the frequency distribution of the registers corresponding to the double trains is identical to that of the fast trains but higher in magnitude. It is due to the fact that fast and double trains pass at a very similar speed. If the slow and the fast trains are compared, the shape of the bands is the same but displaced to the left as a consequence of a lower speed which, according to Eq. (2), means lower frequency.

Analysis of the dynamic effects

For the study of the dynamic effect, the frequency range is extended to the interval $50-1500 \mathrm{~Hz}$. The results obtained for the different types of train are presented in fig. 7. 
a)

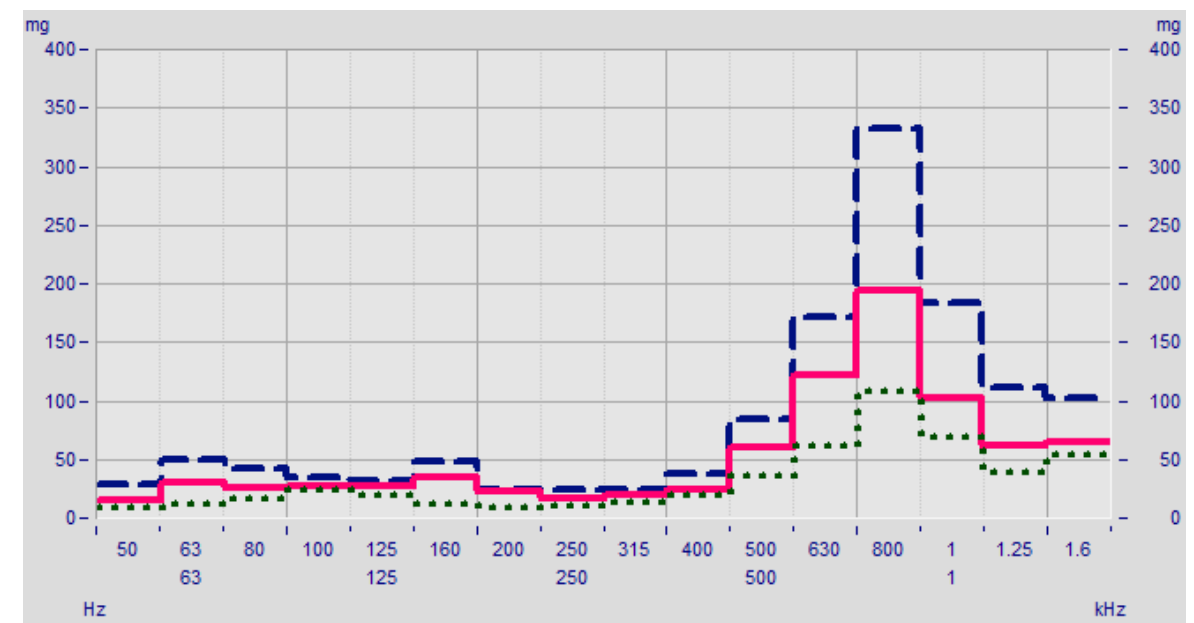

b)

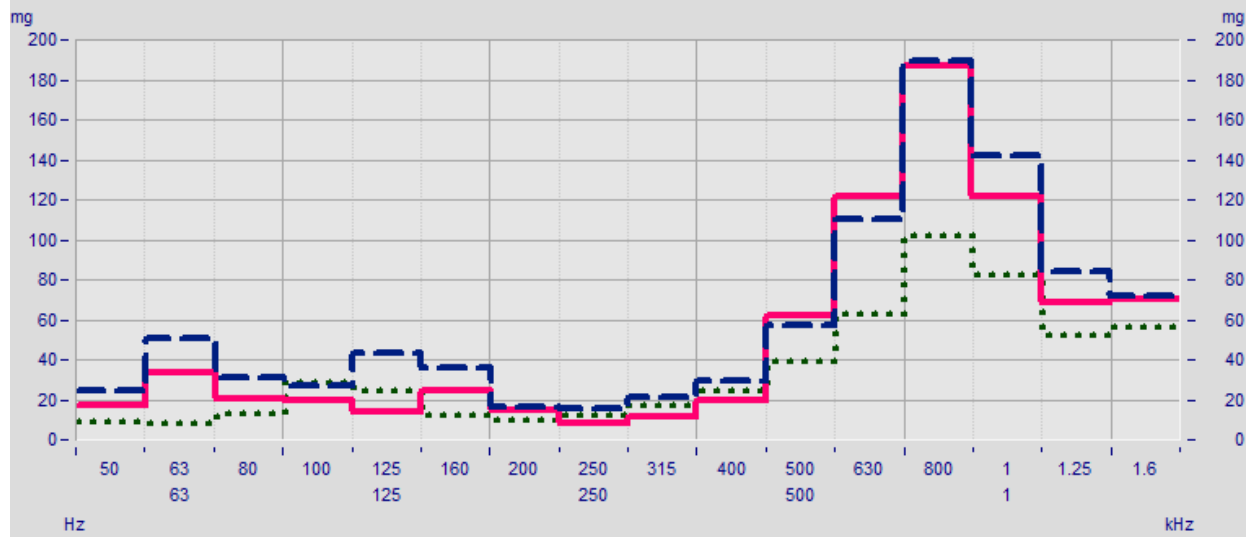

c)

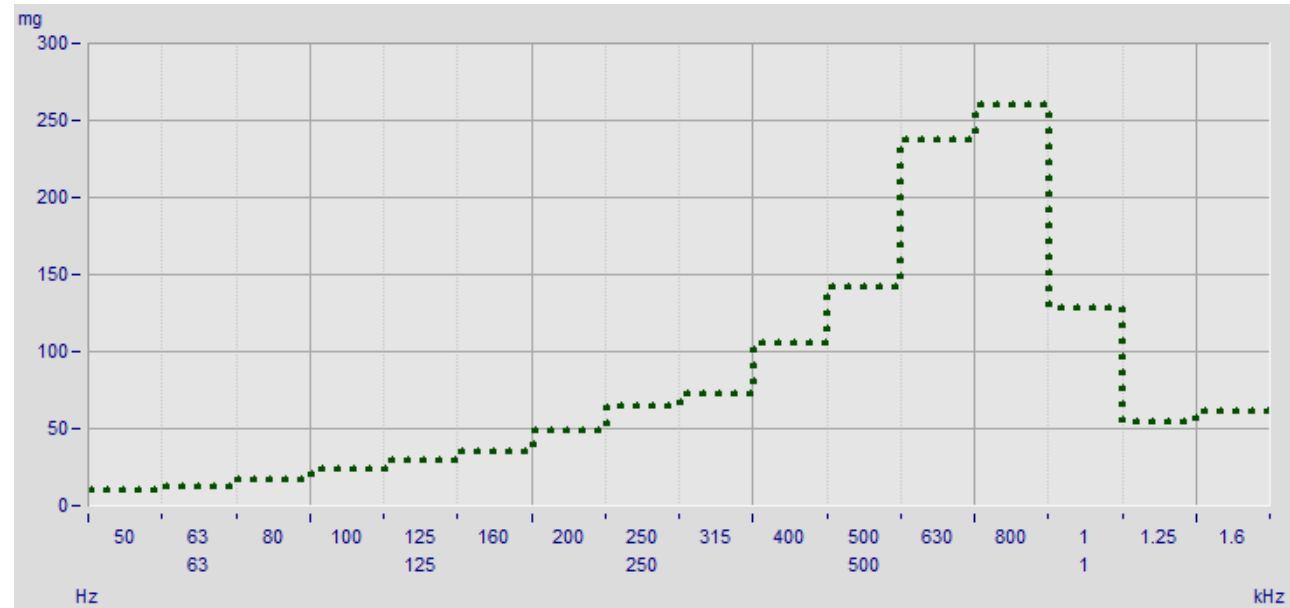

Fig.7. Accelerations on the sleeper center represented in third-octave bands for the Vehicle S-102 (a); S-103 (b); S-120 (c). Fast train( $\square)$, Slow train ( $\cdots)$, Double Train (---).

From the results in fig.7, several eigenfrequencies of the system vehicle-track can be identified. These eigenfrequenies have been excited by the dynamic forces induced by the train passage. First, there is a maximum at the $800 \mathrm{~Hz}$ band which is independent of the vehicle type and the speed. Hence, it can be concluded that it is an eigenfrequency of the track: the pin-pin resonance (fpp). According to De Man (2000), this frequency can be calculated with the formula in Eq. (3).

$$
f_{p p}=\frac{\pi}{2 l^{2}} \sqrt{\frac{E I}{m}}
$$


Where E is the Young's modulus of the rail steel; I the inertia of the cross section; $m$ the mass per unit of length and 1 the distance between two adjacent sleepers. In the case of a UIC-60 rail and a sleeper separation of $0.6 \mathrm{~m}, \mathrm{fpp}=832 \mathrm{~Hz}$. Since this number falls into the mentioned band, the pin-pin resonance results perfectly identified in the frequency spectra.

In the high speed vehicles (S-102 and S-103), other relative maximums appear near the $160 \mathrm{~Hz}$ band in the case of fast vehicles and around the $100 \mathrm{~Hz}$ band for the slow vehicles. This excitation corresponds to the sleeper-passage frequency (fps), which can be calculated as the quotient of the train speed and the separation of two contiguous sleepers. Kourioussis et al. (2011) mention that this phenomenon is insignificant in the ground registers although in the studied case is clearly identified in the acceleration spectra on the sleepers. The value of this frequency is presented in table 4 for each of the studied trains.

\begin{tabular}{|c|c|c|}
\hline & & Frequency (Hz) \\
\hline \multirow{3}{*}{ S-102 } & Fast & 138 \\
\cline { 2 - 3 } & Slow & 105,1 \\
\cline { 2 - 3 } & Double & 133,8 \\
\hline \multirow{2}{*}{ S-103 } & Fast & 143,1 \\
\cline { 2 - 3 } & Slow & 99,5 \\
\cline { 2 - 3 } & Double & 134,3 \\
\hline S-120 & Unique & 78 \\
\hline
\end{tabular}

Table 4. Sleeper-passage frequencies

De Man (2002) states that other natural frequencies such as rail eigenfrequencies can be excited in the same frequency bands of the sleeper- passage frequencies. It will cause a sum of the excitations in the corresponding bands. It can be demonstrated that the excitation produced in the $100-160 \mathrm{~Hz}$ band is caused by the passage of the train over the sleepers since it changes with the vehicle speed. If the excitation had been caused by the eigenmodes of the infrastructure elements, the frequency would have remained invariable with the train speed as demonstrated in the pin-pin resonance.

In addition, Connolly et al. (2014) state that other eigenfrequencies related to the resonance of different dynamic systems (e.g. rail/sleeper-ballast and rail/railpad) may appear within the range $80-800 \mathrm{~Hz}$. The excitation derived from the resonant frequencies can be overlapped to other effects which result more evident such as the pin-pin resonance or the sleeper passage frequencies. It does not imply that these secondary excitations could be neglected but that their precise identification is not as evident since it appears masked by other dominant frequencies.

Finally, it is important to mention the P2 frequency (fp2), which corresponds to the natural frequency of the system formed by the unsprung masses of the vehicle and the track. This frequency is of utmost importance because of its strong influence in the development of the rail corrugation, fixing the wavelength of this defect according to Grassie and Kalousek (1993). Cox et al. (2008) proposed Eq.4 to calculate this frequency.

$$
f_{p 2}=\frac{1}{2 \pi} \sqrt{\frac{k_{v}}{m_{u}}}
$$

In which $\mathrm{Kv}$ is the track vertical stiffness and mu the unsprung mass of the vehicle. According to previous experiments performed by ADIF, the vertical stiffness of the track in the stretch where the accelerations were measured is near $110 \mathrm{kN} / \mathrm{mm}$. On the other hand, the mass of the unsprung masses varies in the range 1500-2000 kg for Spanish high speed vehicles (Melis (2008), Galvín and Domínguez (2010)). It results in a $\mathrm{P} 2$ frequency of $35-40 \mathrm{~Hz}$, which is not evident in the sleeper acceleration registers. According to the deductions from fig. 7 presented in section 4.1, the excitation in these bands is caused by the axle passage moving at the train speed.

\section{Conclusions}

On the basis of the results obtained from the frequency analysis of the infrastructure accelerations induced by the different trains in the high speed track Madrid-Barcelona-French Border, the next conclusions can be presented:

- The mean average PSD of the induced accelerations reaches its maximum for fast double trains, followed by fast simple trains and by slow simple trains in this order. Moreover, the mean average PSD of the accelerations induced by the vehicle S-103 are higher than for the vehicle S-102 and the lowest are caused by the passage of the vehicle S-120. The mean average PSD has the same trend as the net weight (wi) for the different vehicles studied (wS-103 > wS-102 > wS-120). 
- The accelerations originated by the moving quasi static load have been identified in the frequency spectra of the representative accelerograms for each type of train. As expected, these excitations appear in the frequency bands associated to the passage of axles and bogies.

- Two dynamic effects have been also identified in the acceleration spectra: the sleeper-passing frequency and the pin-pin resonance. Other resonant effects such as the P2 frequency or those related to the dynamic systems rail/sleeper-ballast and rail/railpad could not be solely distinguished. However, the frequency bands in which these phenomena appear have been identified for this case.

- The global behavior of a high speed ballasted track has been thoroughly analyzed in frequency domain. The real acceleration data sets can become a useful support for the development of models to predict vibrations induced by trains in the railway infrastructure.

\section{Acknowledgements}

This research is included in the project HD-BALLAST, funded by the Spanish Ministry of Economy and Competitiveness. The authors wish to thank the professionals of ADIF (Spanish Railroad Manager) and UPM (Polytechnic University of Madrid) their implication and constant support, during the development of the project and in the experimental campaign.

\section{References}

[1]. Auersch, L., 2005. The excitation of ground vibration by rail traffic: theory of vehicle-track-soil interaction and measurements of high-speed lines. Journal of sound and vibration, Volume 284, pp. 103-132.

[2]. Auersch, L., 2006. Ground vibration due to railway traffic. The calculation of the effects of moving static loads and their experimental verification. Journal of sound and vibration, 293(3-5), pp. 599-610.

[3]. Auersch, L., 2010. Theoretical and experimental excitation force spectra for railway-induced ground vibration: vehicle-track-soil interaction, irregularities and soil measurements. Vehicle System Dynamics, 48(2), pp. 235-261.

[4]. Connolly, D. et al., 2014. Scoping prediction of re-radiated ground-borne noise and vibration near high speed rail lines with variable soils. Soil Dynamics and Earthquake Engineering, Volume 66, pp. 78-88.

[5]. Cox, S., Wang, A. \& Adedipe, A., 2008. Survey of Metro Excitation Frequencies and Coincidence of Different Modes. Notes on Numerical Fluid Mechanics and Multidisciplinary Design, Volume 99, pp. 78-85.

[6]. De Man, A., 2000. Pin-pin resonance as a reference in determining ballasted track vibration behaviour. Heron, 45(1), pp. 35-51.

[7]. De Man, A., 2002. Dynatrack. A survey of dynamic railway track properties and their quality, Delft: Technische Universiteit Delft.

[8]. Degrande, G. \& Schillemans, L., 2001. Free field vibrations during the passage of a Thalys HST at variable speed. Journal of Sound and Vibration, Volume 247, pp. 131-144.

[9]. Ditzel, A., Herman, G. \& Drijkoningen, G., 2001. Seismograms of moving trains: comparison of theory and measurements. Journal of Sound and Vibration, Volume 248, pp. 635-652.

[10]. Galvín, P. \& Domínguez, J., 2007. High-speed train-induced ground motion and interaction with structures. Journal of Sound and Vibration, 307(3-5), pp. 755-777.

[11]. Galvín, P. \& Domínguez, J., 2009. Experimental and numerical analyses of vibrations induced by high-speed trins on the CórdobaMálaga line. Soil dynamics and earthquake engineering , 29(4), pp. 641-657.

[12]. Grassie, S. L. \& Kalousek, J., 1993. Rail corrugation: characteristics, causes and treatments. Journal of Rail and Rapid Transit, Volume 207, pp. 57-68.

[13]. Lombaert, G., Degrande, G., Kogut, J. \& François, S., 2006. The experimental validation of a numerical model for the prediction of railway induced vibrations. Journal of Sound and Vibration, 297(3-5), pp. 512-535.

[14]. Melis, M., 2008. Apuntes de introducción a la dinámica vertical de la vía y a las señales digitales en ferrocarriles. First Edition ed. Madrid: Universidad Politécnica de Madrid.

[15]. Xia, H., De Roeck, G., Zhang, N. \& Maeck, J., 2003. Experimental analysis of a high-speed railway bridge under Thalys trains. Journal of Sound and Vibration, 268(1), pp. 103-113.

[16]. Xianzhang, L. et al., 2009. Field experiment of subgrade vibration induced by passing train in a seasonally frozen region of Daqing. Earthquake Engineering and Engineering Vibration, 8(1), pp. 149-157. 